\title{
المفردات العربية وطرق التعليم المناسبة بما
}

\section{Rappe $^{1}$, Syamsuri ${ }^{2}$, Muhammad Napis Djuaeni ${ }^{3}$}

1,2,3Universitas Islam Negeri Alauddin Makassar

1,2,3Jalan H. M. Yasin Limpo No. 36 Romang Polong-Gowa, Sulawesi Selatan

Email: muhammadrappe.mr@gmail.com², syamsuri.jufri@gmail.com² ${ }^{2}$, napis.djuaeni5@gmail.com ${ }^{3}$

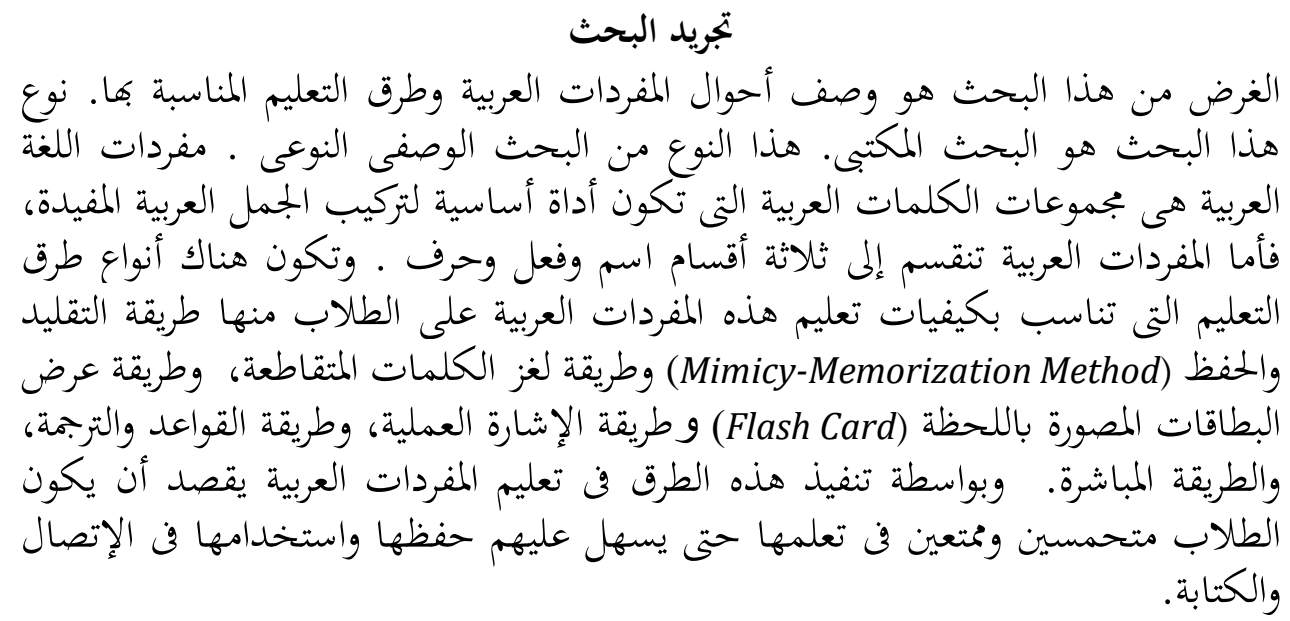

Abstrak

Tujuan penelitian ini adalah mendeskripsikan hal ihwal kosa kata-kosa kata Bahasa Arab dan metode pembelajarannya yang relevan. Jenis penelitian ini adalah penelitian pustaka (Library Research) dengan pendekatan deskriptif kualitatif. Mufradat bahasa Arab adalah kumpulan kata-kata bahasa Arab yang menjadi alat utama untuk menyusun kalimat-kalimat dalam bahasa Arab. Adapun jenis kata/mufradat dalam bahasa Arab terbagi tiga yaitu isim (kata benda dan sejenisnya), fi'il (kata kerja), dan harf (preposisi). Terdapat beberapa jenis metode yang relevan dalam pembelajaran mufradat yaitu, metode min-mem, metode flash card, metode teka-teki silang, metode unjuk kerja, metode qawaid tarjamah, dan metode langsung. Metode-metode tersebut dapat dipilih sebagai alternatif untuk membelajarkan mufradat bahasa Arab sesuai dengan tingkat kemampuan dan kondisi psikologis peserta didik. Melalui penerapan metode-metode tersebut peserta didik diharapkan dapat mempelajari mufradat bahasa Arab dengan penuh semangat dan rasa senang sehingga mereka mudah menghafalkannya dan menggunakannya dalam berkomunikasi dan menulis.

$$
\begin{aligned}
& \text { الكلمات الأساسية } \\
& \text { المفردات العربية، طرق التعليم، الطلاب الكية }
\end{aligned}
$$

How to Cite: Rappe, Syamsuri, Djuaeni, M. N. (2021). المفردات العربية وطرق التعليم المناسبة L6. Lentera Pendidikan : Jurnal Ilmu Tarbiyah dan Keguruan, 24(2), 264-275. https://doi.org/ 10.24252/lp.2021v24n2i9. 
اللغة هي أداة من أدوات الاتصال للإنسان. والسلوك لاكتساب أو إتقان اللغة يتحقق بطريقتين، طريقة الوعي و طريقة غير الوعي. إتقان اللغة بطريقة الوعى يتحقق من خلال تعلمها كلغة ثانية أو أجنبية

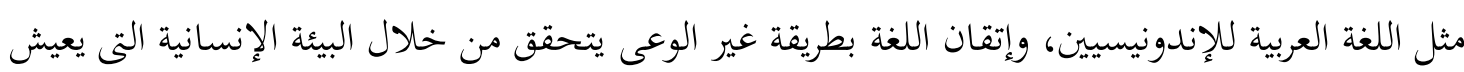

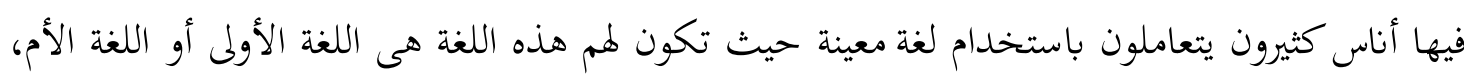

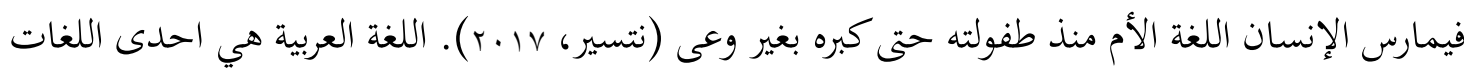
الأجنبية التي يتعلمها الكثيرون من الإندونيسيين. فمن الضرورة لمم دراسة عناصرها الأساسية كطريقة بتحاه إتقاها، ومن عناصر اللغة الضرورية عنصر مفردات. المفردات هي احدى عناصر اللغة التي يجب على على كل

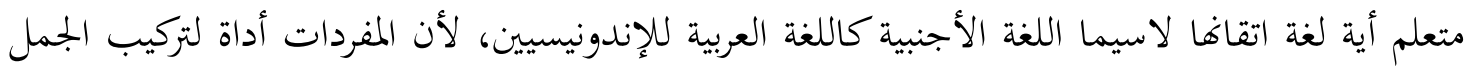
المتنوعة من اللغة لقصد التعبير عن أغراض الإنسان (وا مونا، 11 ـr). إتقان المفردات الجيد سيساعد المتعلم

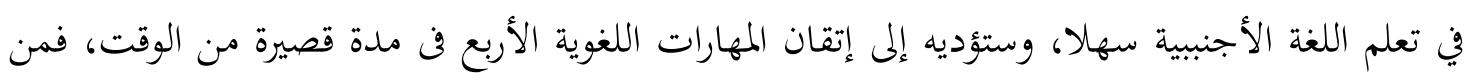

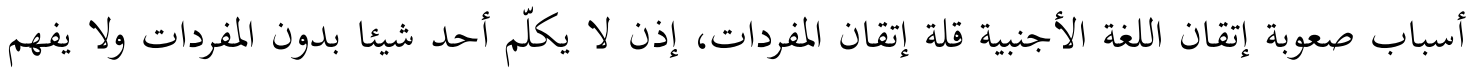

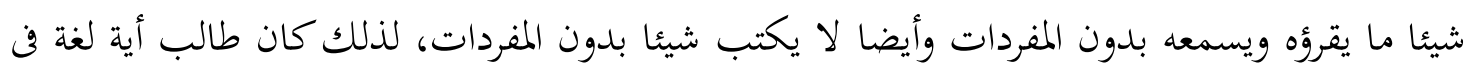
حاجة كبيرة إلى إتقان المفردات الكثيرة، وفى تحقيق هذا الغرض يحتاج الطالب الم مساعدة معلم اللغة المتأهل لتطوير مفرداته عاجلا باستخدام طرق مناسبة بتعليم تلك المفردات (مستقيم، 11 ــ). تعليم المفردات العربية له طرق متنوعة ينبغى أن يستخدمها المعلم لمساعدة المتعلمين في تطوير إتقاهم عليها مثل طريقة التقليد والحفظ وطريقة لغز الكلمات المتقاطعة، وطريقة عرض البطاقات المصورة باللحظة وطريقة الإشارة العملية، وطريقة القواعد والترجمة، والطريقة المباشرة.

منهج البحث

نوع البحث هو البحث المكتبى (Library research). وهي بحث تتم معالجة بياناته من خلال

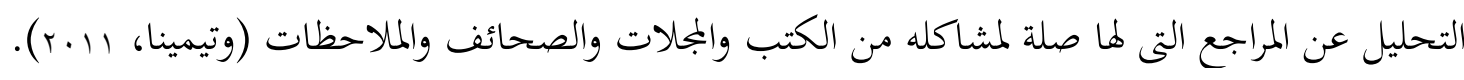
هذا النوع شعبة من مداخل البحث الوصفي النوعي لما فيه بيانات يتم جمعها في شكل وصفى فقط ونط أى لا

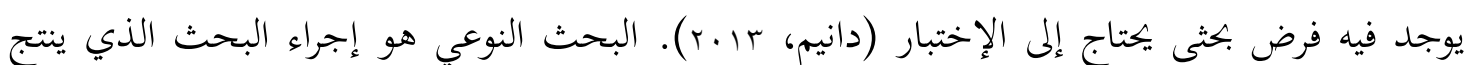

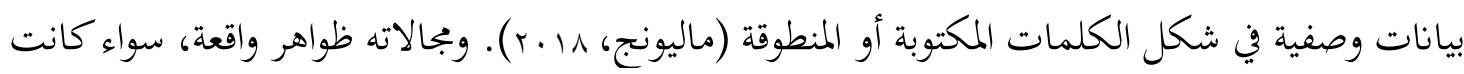
ظواهر طبيعية أو ظواهر هندسة بشرية (ماليونج، 11 ·r). ومصدر البيانات ينقسم الى قسمين مصدر أولي ومصدر ثانوي. فالمصدر الأولي هو المصدر الأساسي من الكتب والمجلات العلمية التى تحلل فيها الكلمات العربية وطرق تعليمها، والمصدر الثانوي هو مصدر البيانات الإضافية لاستكمال وتقوية المصادر الأولية.

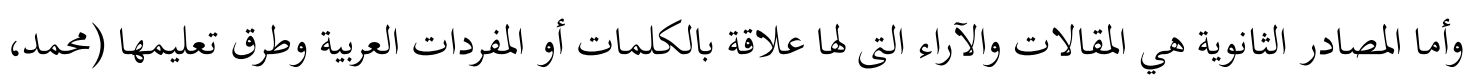




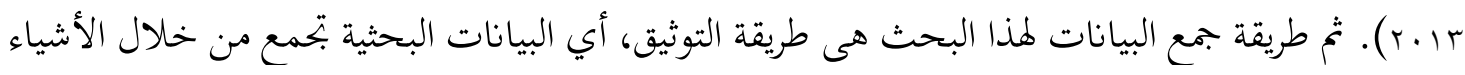

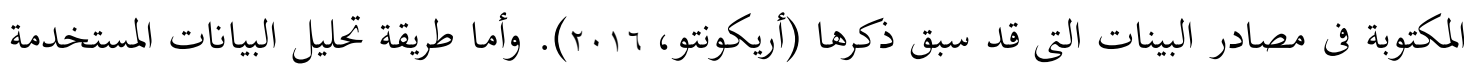

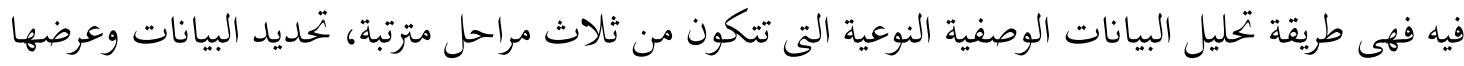

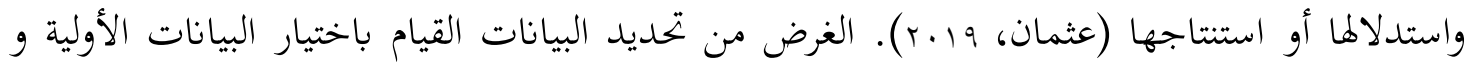

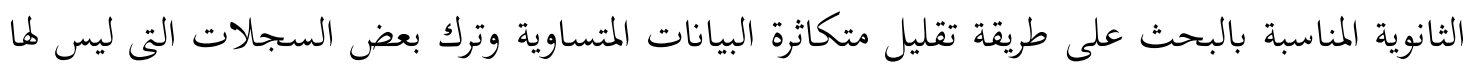
علاقة واثقة لتركيز البحث. و الغرض من عرض البيانات القيام بوصف سردي مترتب معقول من البيانات المحددة. والغرض من استنتاج البيانات القيام بتقديم نتائج بحثية.

\section{وصف المفردات العربية}

اللغة العربية هي احدى اللغات الأجنبية التي يتعلمها الكثيرون من الإندونيسيين. فمن الضرورة لمم

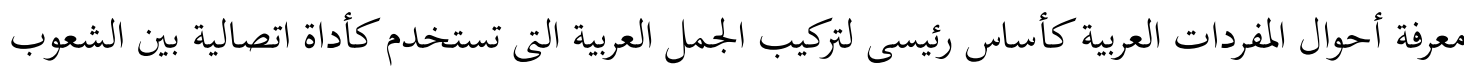

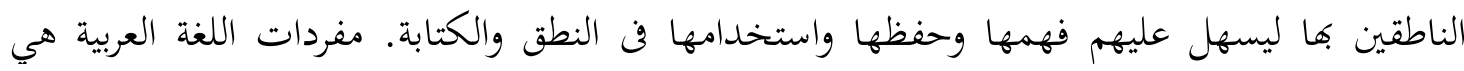

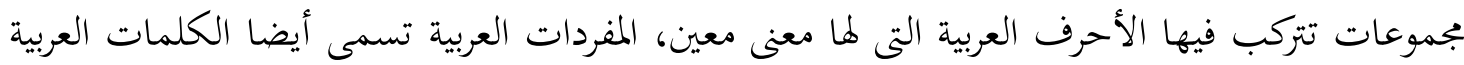

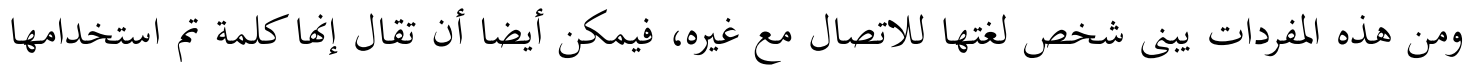

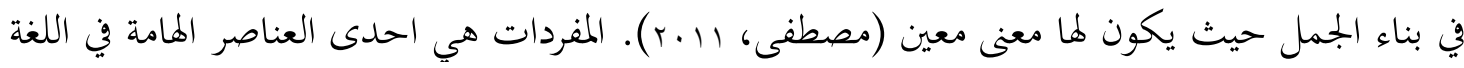

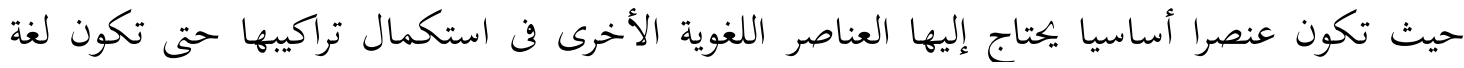

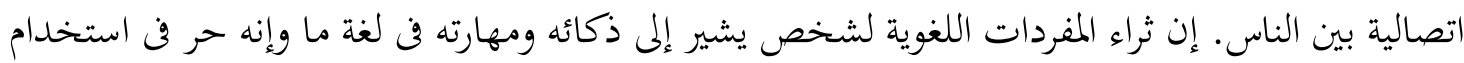
تلك اللغة بالطلاقة شفويا أو كتابيا (عبد الحميد، با. ـr).

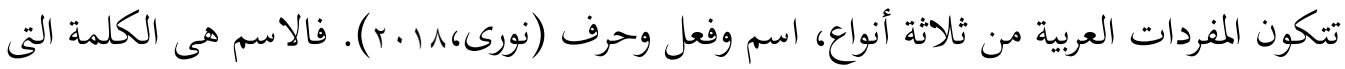

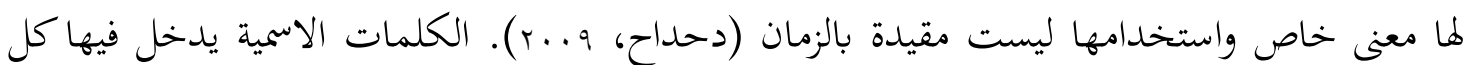

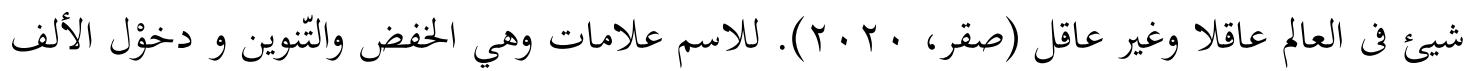

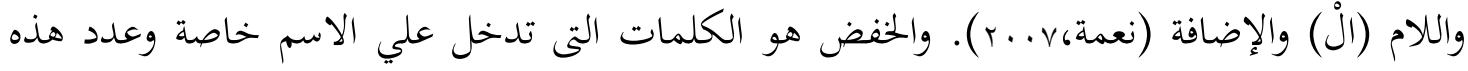

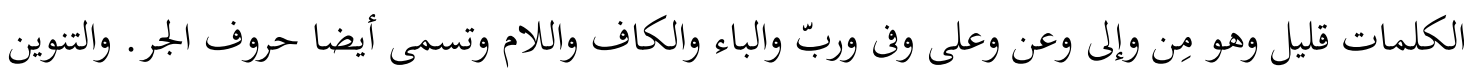

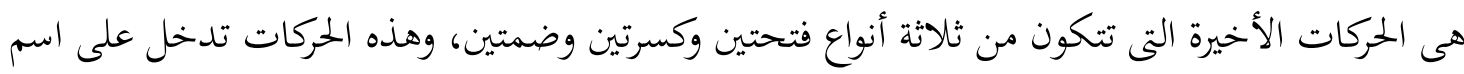

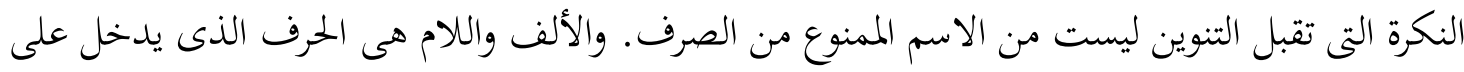

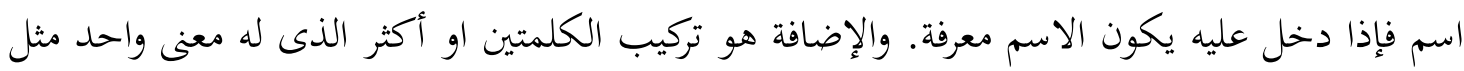

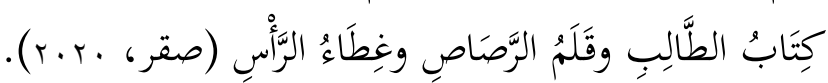

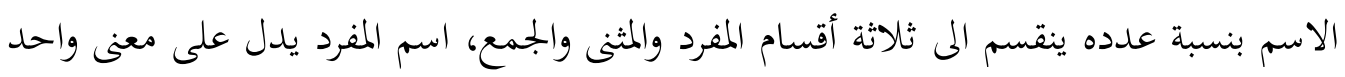

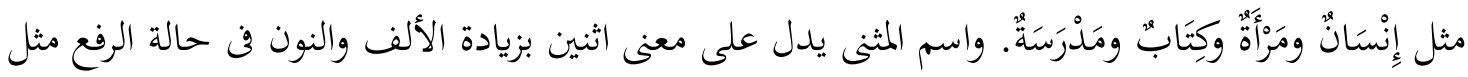




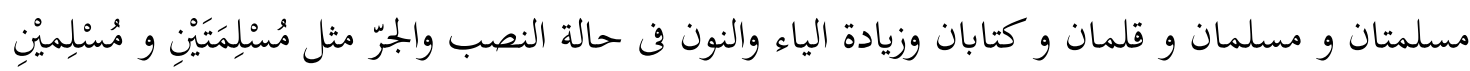

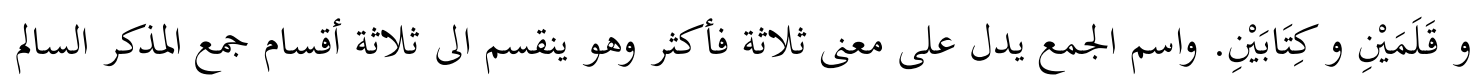

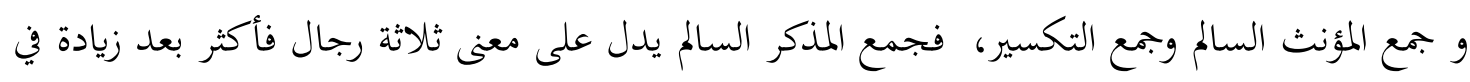

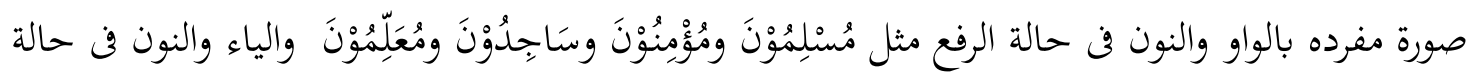

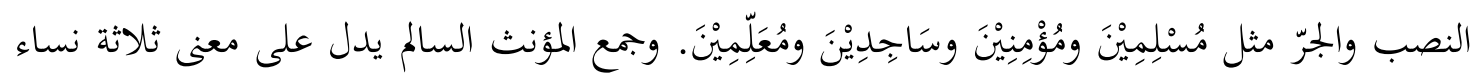

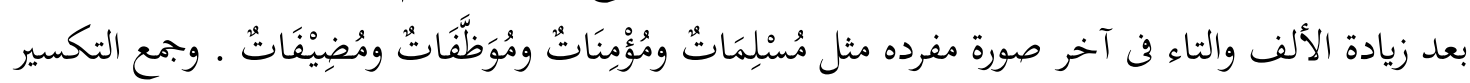

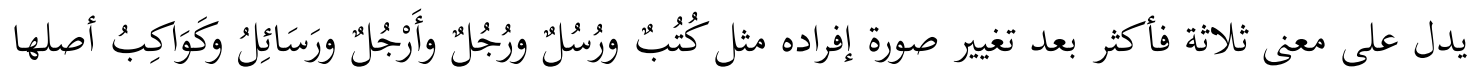

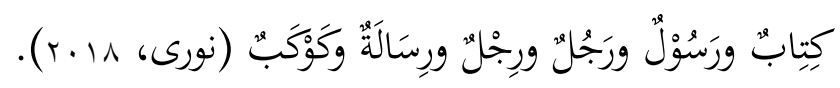

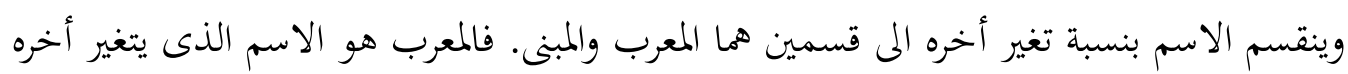

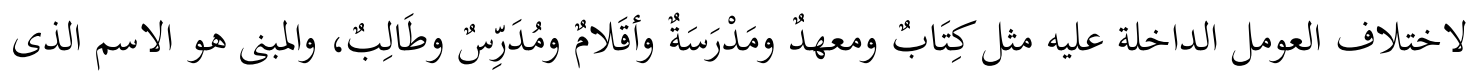

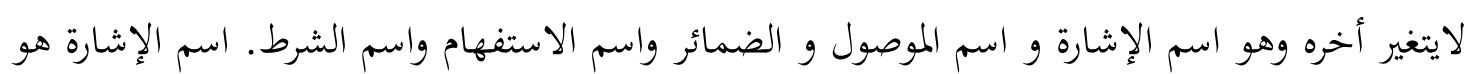

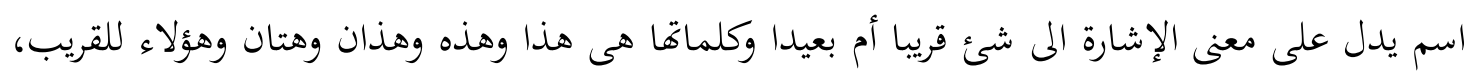

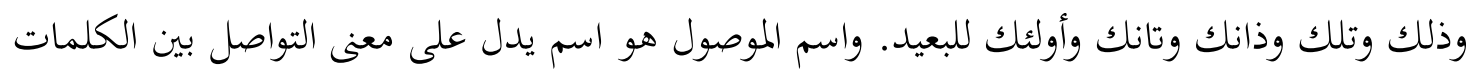

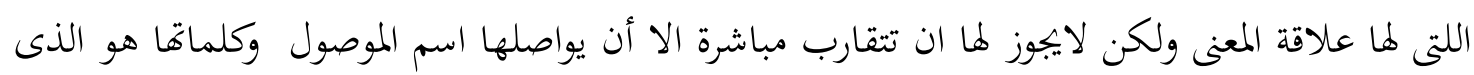

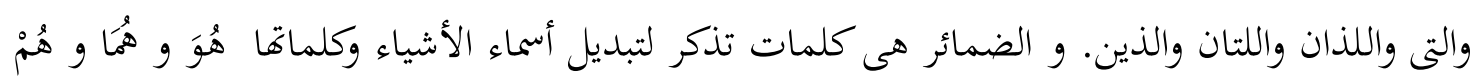

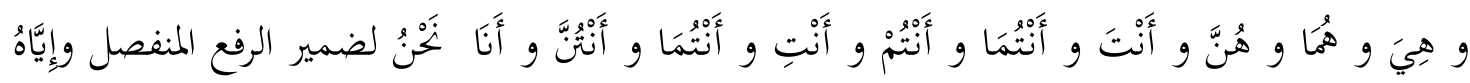

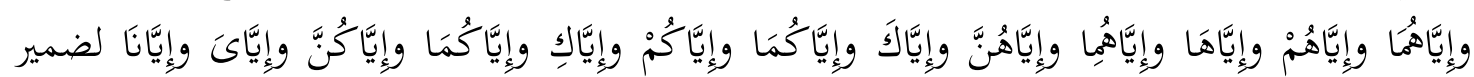

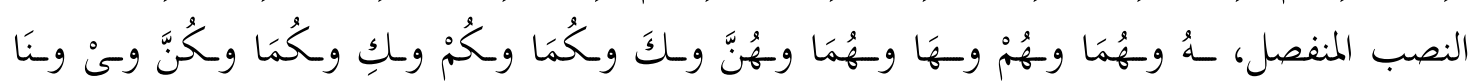

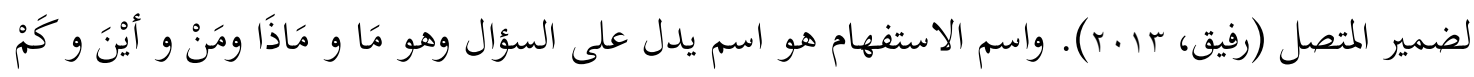

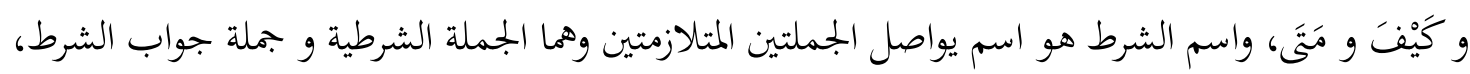

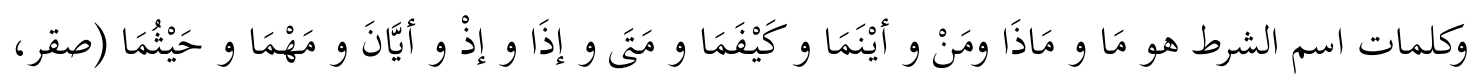
. (r. r.

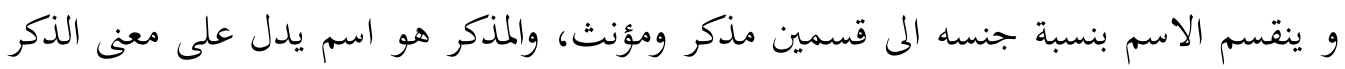

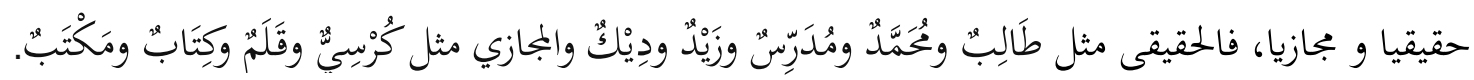

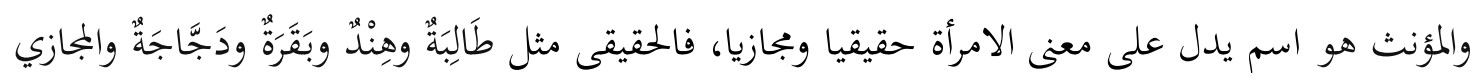

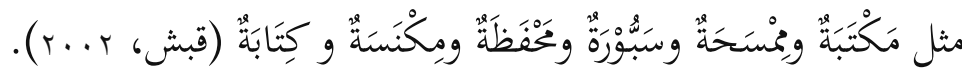

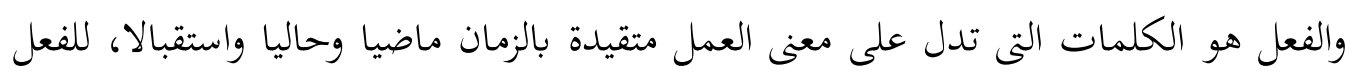

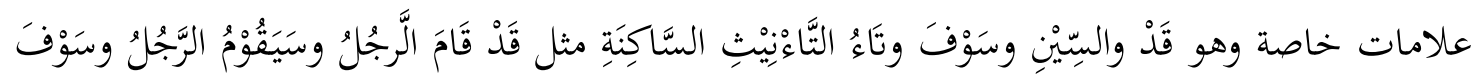

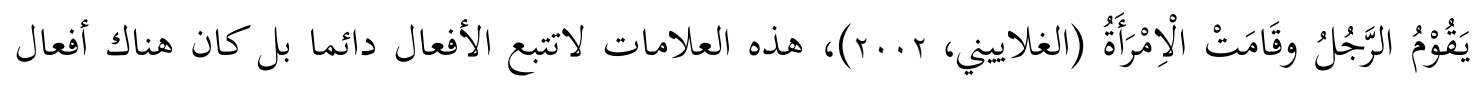




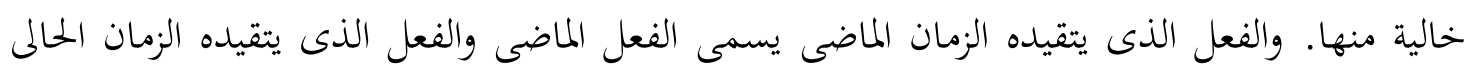

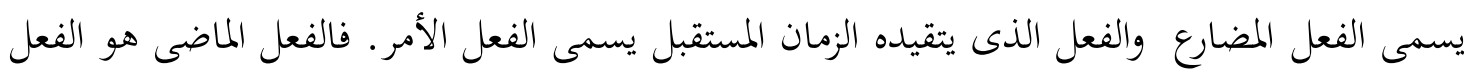

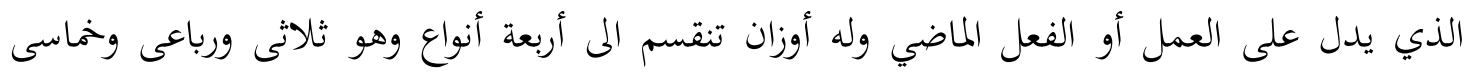

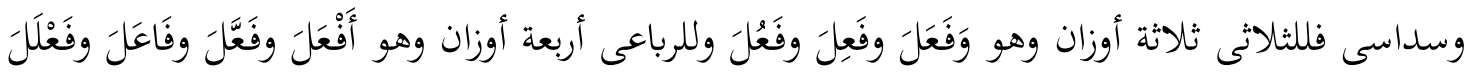

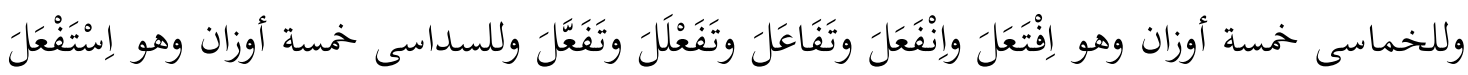

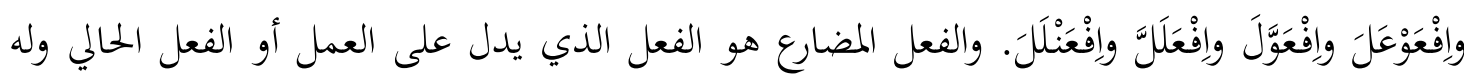

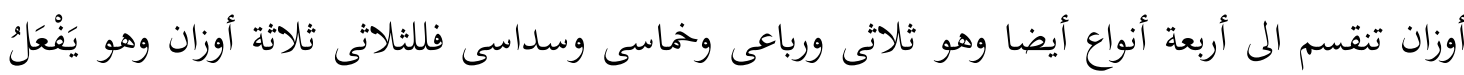

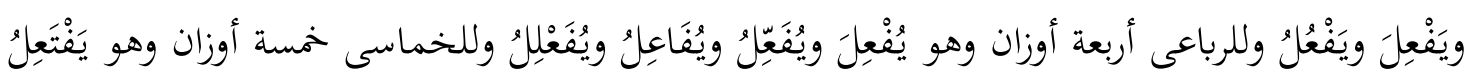

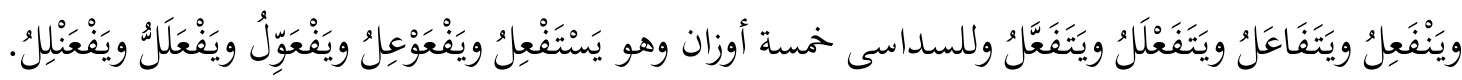

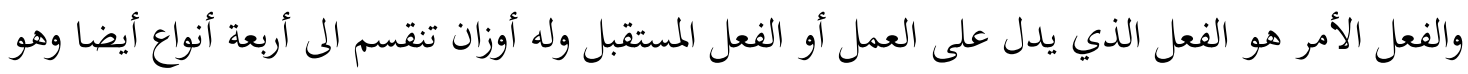

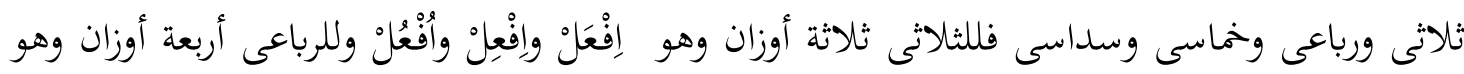

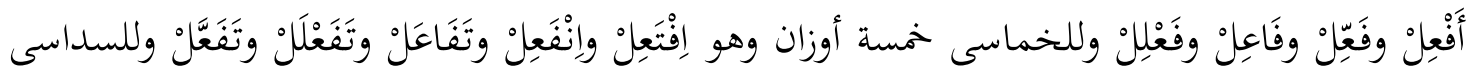

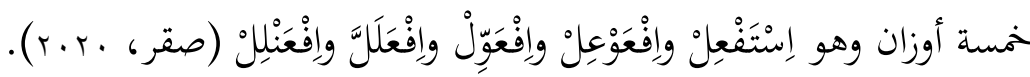

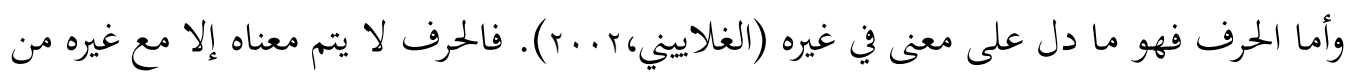

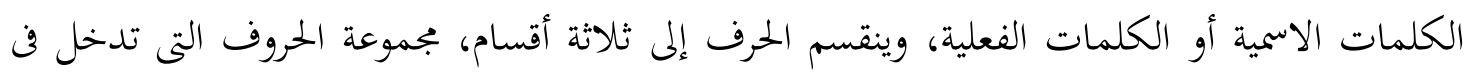

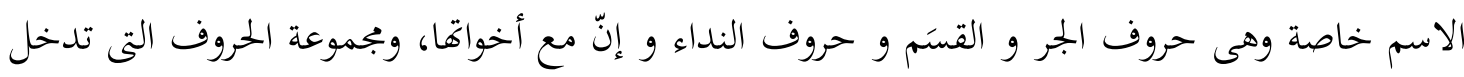

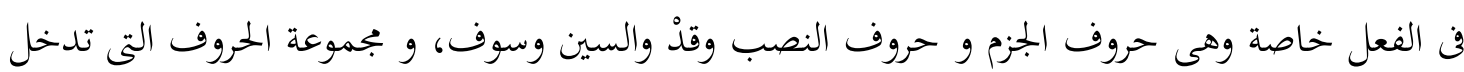

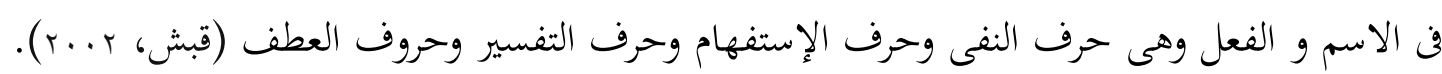

\section{طرق التعليم المناسبة بتعليم المفردات العربية}

اللغة العربية هي احدى اللغات الأجنبية التي يتعلمها العديد من المسلمين الإندونيسيين. فمن

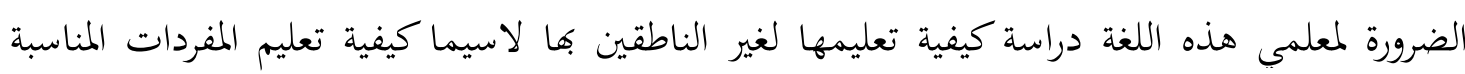

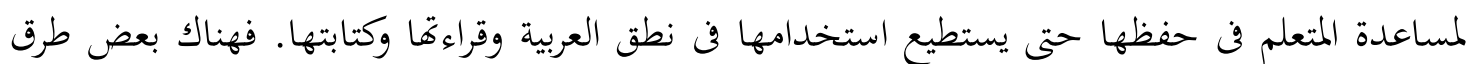
متنوعة متعة مناسبة بتعليم المفرات العربية وهى طريقة التقليد والحفظ (Mimicy-Memorization Method) وطريقة لغز الكلمات المتقاطعة، وطريقة عرض البطاقات المصورة باللحظة (Flash Card) وطريقة الإشارة

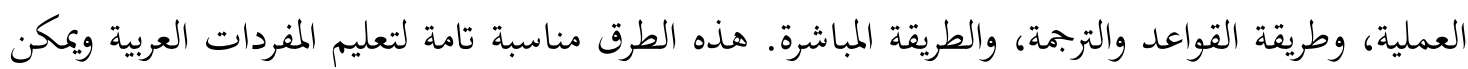

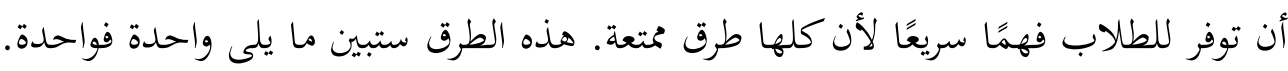

ا . . طريقة التقليد والحفظ (Mimicy-Memorization Method) خطوات تنفيذ هذه الطريقة فيما يلي: 
أ. يقرأ المعلم المفردات التي سيتم تدريسها واحدة فواحدة بطلاقة وفصاحة.

ب. يقلد المتعلمون كلمات معلمهم مراراً وتكراراً حتى يهفظوها. ت. يقوم المعلم بالإشارة إلى بعض الطلاب عشوائيا لذكر المفردات التى قد سبقت قراءقا مع المعلم

$$
\text { للتحقق من اتقان الطلاب عليها. }
$$

ث. يمكن للمعلم التحول إلى مفردات أخرى إذا كان الطلاب قد اتقنوا المفردات السابقة التى تح

\section{تعلمها.}

ج. يعطي المعلم الاستنتاج من الأنشطة التعليمية التي تم القيام بها (عفيفة · ب · ). والضمير الرئيسى من هذه الطريقة بالنظر إلى خطوات تدريسها هو أن تكون قراءة المعلم واضحة

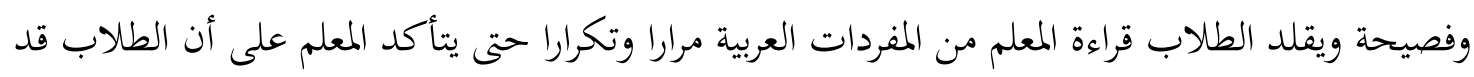

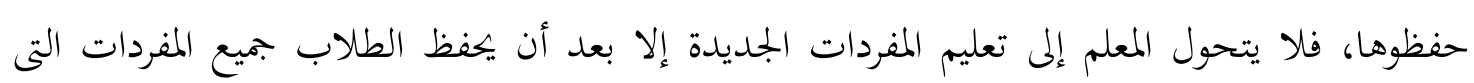

يتعلموها.

r . F مريقة عرض البطاقات المصورة باللحظة (Flash Card)

طريقة عرض البطاقات المصورة باللحظة (Flash Card) هي طريقة تعليم المفردات العربية على

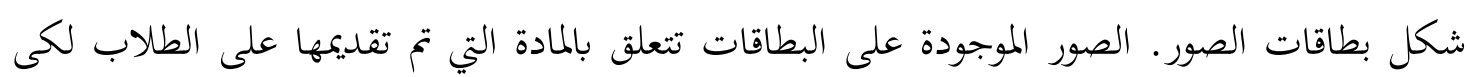

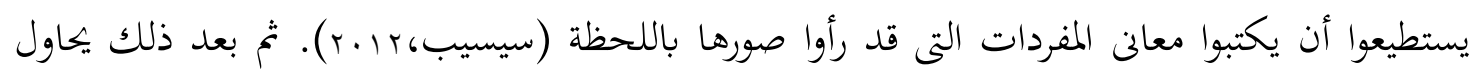

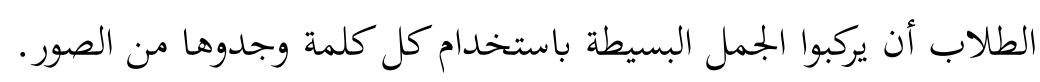

$$
\text { فخطوات تنفيذ هذه الطريقة هي: }
$$

أ. يقوم المعلم بإعداد صور مطابقة للمادة مع الأشياء المحتاجة إليها ليتم لصق الصور على السبورة.

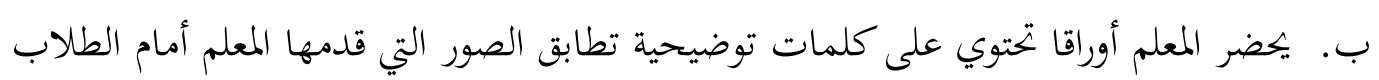
باللحظة.

ت. يقوم الطلاب بدورهم، وهو أحد الطلاب يتلو المفردات المطابقة بالصور للآخرين بشكل

$$
\text { صحيح ودقيق في بجموعات صغيرة أو بجموعة كبيرة ليكتبوها. }
$$

ث. يجب على الطلاب حفظ الكلمات العربية بالنظر إلي الصور المقدمة عليهم شفهيًا واحدة

$$
\text { فواحدة }
$$

ج. يلصق الطلاب الكلمات العربية مع الصور المطابقة بشكل صحيح

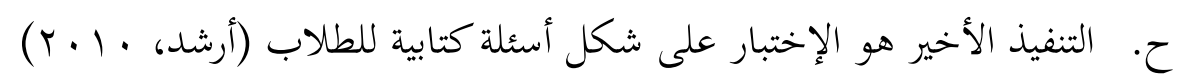


r. م. مريقة لغز الكلمات المتقاطعة

لغز الكلمات المتقاطعة هي شعبة من طرق اللعبة، هذه الطريقة فيها فارغات على شكل مربع تحتاج إلى إملائها بالكملمات العربية المطابقة متنزلة و مستقيمة بكتابتها حرفا فحرفا. فلذلك ، يعد إملاء

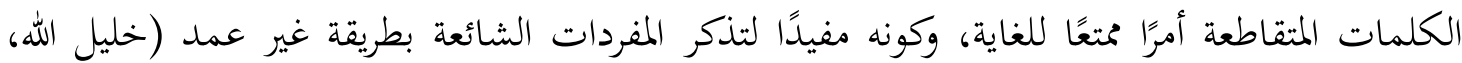

\section{خطوات تنفيذ لعبة لغز الكلمات المتقاطعة وهي:}

أ. يوضح المعلم أولاً لعبة لغز الكلمات المتقاطعة للطلاب أمام الفصل، ثم يخبرهم كيف يلعبوها.

$$
\text { ب. يقوم المعلم بتقديم الكلمات المتقاطعة حسب المادة التي سيتم تدريسها. }
$$

ت. تبعد إعداد المادة، يقوم المعلم بتقديم نموذج الأسئلة وأجوبتها من الكلمات العبية التى ستملأ

$$
\text { في الفارغات المربعة. }
$$

ث. يمكن أن تكون الإجابة على لغز الكلمات المتقاطعة من اسم أو فعل. وهذا بالطبع يختلف عن لغز الكلمات المتقاطعة اللاطنية لأن المفردات العربية هي الكتابات المتصلة لا يمكن فصل

$$
\text { حرف من حروف أخرى. }
$$

يكتب المعلم لغز الكلمات المتقاطعة على السبورة ولكن ربما إذا كان مكتوبًا على السبورة سيستغرق وقتًا طويلاً، فسيكون ذلك فعالاً إذاكانت الكلمات المتقاطعة قد كتبت سابقةً على لئ ورقة كبيرة حيث تُعرض على السبورة عند التدريس. يجب على جميع الطلاب إملاء الفارغات

$$
\text { المربعة على ورقة لغز الكلمات المتقاطعة. }
$$

ح. بعد أن ينهي الطلاب السؤال، يُطلب منهم عمل لغز الكلمات المتقاطعة التى تتضمن أسئلة وأجوبة. وإن لم يكن الوقت كافيًا، فسيتم حل لغز الكلمات المتقاطعة في المنزل. خ. في الاجتماع التالي، تبادل نتائج الألغاز المتقاطعة بين الطلاب في نفس الفصل لتفتيشها وتقديم الاقتراح للإصلاحات، ثم بعد ذلك أعيدت إلى أصحاها. د. تقويم ألغاز متقاطعة من قبل المعلم. ذ. ـيقدم المعلم التعليقات والتوضيحات حول واجبات الطلاب برمتها من الكلمات المتقاطعة التي

$$
\text { قد أجاها الطلاب (ميديكاواتي، r ا ب r). }
$$

وبواسطة هذه الطريقة يرجى من الطلاب أن يجفظوا المفردات العبية كثيرا من الكلمات التى وجدوها في لعبة لغز الكلمات المتقاطعة وخاصة عندما عرفوا الأجوبة الصحيحة من المعلم. 
طريقة الإشارة العملية هي طريقة التدريس من خلال إظهار عملية معينة إما بشكل مباشر أو من خلال استخدام وسائط تعليمية ذات صلة بالمادة التي تتم دراستها، سواء كانت فعلية أو مقلدة مصحوبة بتفسيرات شفهية.

$$
\text { خطوات تنفيذ طريقة الإشارة العملية في تعليم المفردات العربية هي: }
$$

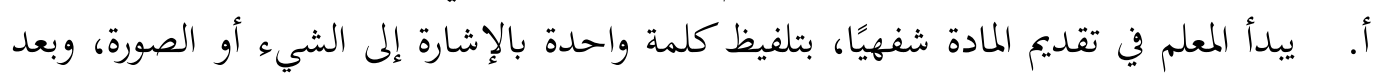

ذلك يقلدها الطلاب عدة مرات حتى يصح نطقها ويفهمون معانيها.

ب. بعد أن يشعر المعلم بأن الطلاب قد أتقنوا المادة المقدمة، إما في النطق وإما في فهم المعنى، يُطلب من الطلاب فتح الكتاب المدرسي. ثم يقدم المعلم نصا من القراءات التي تطلب من

$$
\text { الطلاب قراءةًا واحدا فواحدا. }
$$

ت. يقرأ المعلم نص القراءات العربية أمام الفصل أو يستخدم شريط كاسيت أو فيديو، ويستمع

$$
\text { الطلاب إلى الجمل التي يتم تشغيلها أو الانتباه إليها. }
$$

ث. ثم يُطلب من الطلاب محاولة نطق الجمل التي تم سماعها.

ج. الإجابة على الأسئلة أو التمارين في المادة شفهيًا ( يوسف، لو 99 ( ).

يطلب من الطلاب في هذه الطريقة مهارة الكلام التى تبدأ بتقليد تلفيظ المعلم مباشرة أو غير

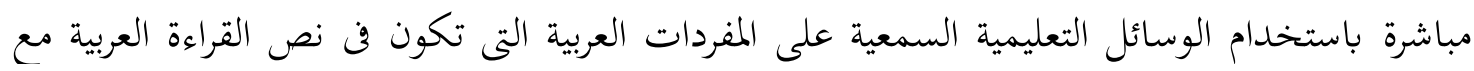
محاولة فهم معانيها، وفن وسط تنفيذ هذه الطريقة يقرأ الطلاب نص القراءة العربية واحدا فواحدا، وفى عقبة هذه الطريقة إعطاء التقويم للطالب علي شكل شفهي. ومن خلال هذه الطريقة يرجى من الطلاب إتقان المفردات المستخدمة فن المادة المقدمة التى تصدر من نص قراءة لكثرة نطقها وسماعها طوال عملية التعليم.

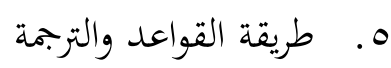

هذه الطريقة هي اشتراك فيها قواعد اللغة العربية وترجمتها من خلال تعليمها وهى تؤكد مهارة القراءة والكتابة والترجمة. ويعترف هذه الطريقة أكثر استخدامها في تعليم اللغة الأجنبية في المدارس

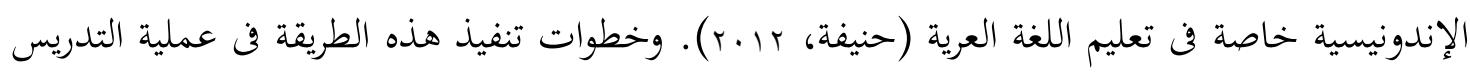

أ. في البداية قام المعلم بتدريس قواعد اللغة العربية من عناصر علم النحو والصرف الواردة فن نص

$$
\text { القراءة العربية. }
$$

ب. يبين المعلم مع الطلاب لكل كلمة واردة في نص القراءة عناصر نحوها وصرفها. 


$$
\text { ت. يترجم المعلم مع الطلاب لكل كلمة واردة في نص القراءة معانيها. }
$$
ث. يقرأ الطلاب نص القراءة قراءة صحيحة عند النحو والصرف ويترجموها إلى اللغة الوطنية (روبينى،

هذه الطريقة تؤكد مهارة القراءات العربية مع معانيها، فيقرأ الطلاب نص قراءة عربية صحيحة لفهمهم عن محلات إعراب كلماتما وبنياتا، وفن نفس الوقت يستطيع الطلاب أن يترجموها. وبواسطة تنفيذ

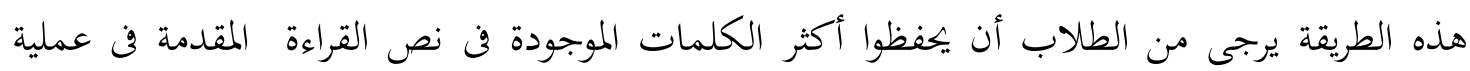
التعليم.

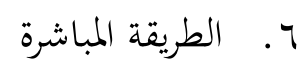

الطريقة المباشرة هي الطريقة التى تعرض فيها مادة اللغة الأجنبية حيث يستخدم المعلم اللغة العربية

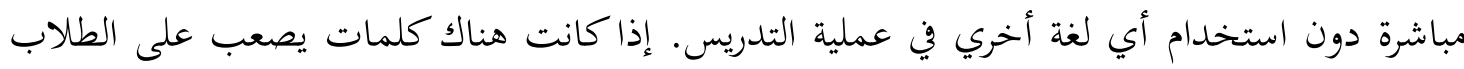

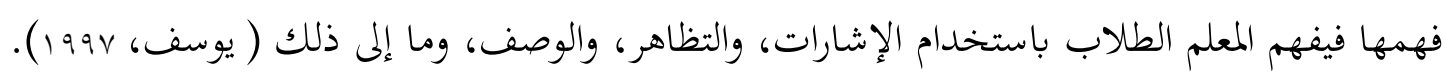
خطوات تطبيق الطريقة المباشرة هي: أ. يبدأ المعلم بعرض المادة شفوياً، قائلاً كلمة واحدة بالإشارة إلى الكائن أو صورة الكائن، وبعد

$$
\text { ذلك يقلده الطالب عدة مرات حتى يصح نطقهم للمفردات وفهم معانيها. }
$$

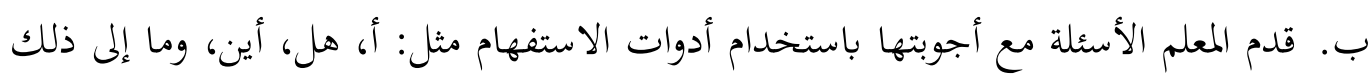

$$
\text { حسب المادة التي تم عرضها. }
$$

ت. بعد أن يشعر المعلم بأن الطلاب قد أتقنوا المواد المعروضة، سواء كانوا في النطق أو في فهم المعنى، يطلب من الطلاب فتح الكتاب المدرسي. فالمعلم يقرأ المادة ويطلب من الطلاب تقليد

$$
\text { قراءته بالتناوب. }
$$

ث. يجيب الطلاب شفويا عن الأسئلة أو التمارين التى تكون في الكتاب الدراسى. ج. يتم إعطاء القراءة العامة التي توافق على مستوى قدرة الطلاب. ح. يعبر الطلاب عن الجمل القصيرة المتنوعة لقصد زيادة مفرداتا بغير عمد.

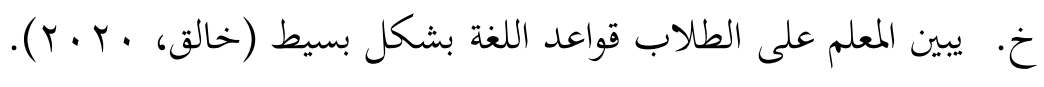

في هذه الطريقة يستخدم المعلم اللغة العربية كلغة اتصالية في عملية التعليم ولايؤذن فيها الطلاب استخدام اللغة الأخرى دون اللغة العربية. فيحفظ الطلاب المفردات العربية بواسطة استخدام هذه الطريقة لسماعها مرارا والنظر إلى الكائنات المقصودة من تلك الكلمات وممارسة نطقها مرارا. 
فمن البيانات السابقة التى تتعلق بالطرق التى تناسب بتدريس المفردات العربية يقدم الكاتبان الخلاصة فيما يلى: ا. المفردات العربية هي مجموعة من الحروف العربية التى جاءت بالمعنى وهي جزء ضروري من عناصر اللغة وبواسطتها ركبت الجمل من اللغة. تتكون المفردات العربية من ثلاثة أقسام، و هي اسم و فعل وحرف. r. الطرق التعليمية المناسبة بتعليم المفردات العربية هي طريقة التقليد والحفظ، وطريقة عرض البطاقات المصورة باللحظة وطريقة لغز الكلمات المتقاطعة، وطريقة الإشارة العملية وطريقة القواعد والترجمة، والطريقة المباشرة. هذه الطرق ستؤدى الطلاب إلى التمتع في تعلم المفردات العربية والتسهيل عليهم لحفظها وتطبيقها في الاتصال. 


$$
\begin{aligned}
& \text { المراجع } \\
& \text { المراجع العربية } \\
& \text { الدحداح، أنطوان. (و ...r). معجم قواعد اللغة العربية في جلدوال ولوحات. لبنان: موسوعة الدحداح فن }
\end{aligned}
$$

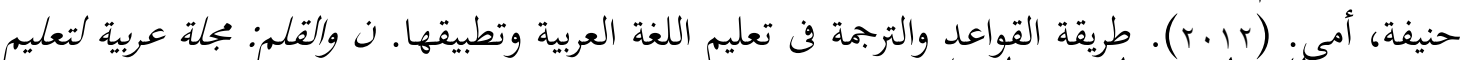

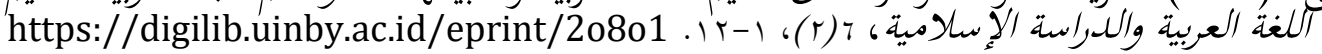

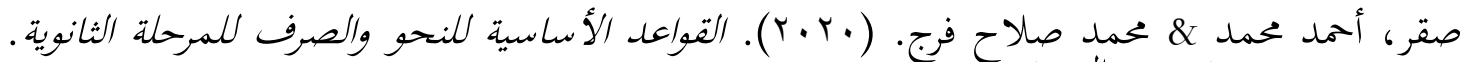

$$
\begin{aligned}
& \text { جمهورية مصر العربية. }
\end{aligned}
$$

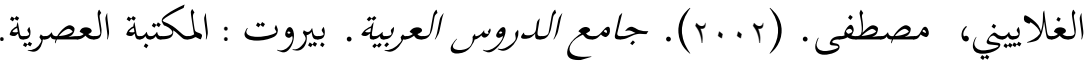

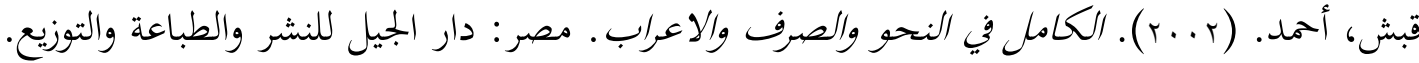

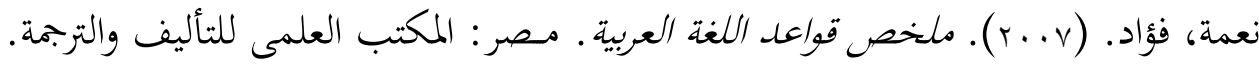

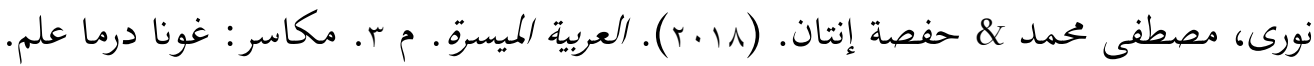

$$
\begin{aligned}
& \text { المراجع الأجنبية }
\end{aligned}
$$

Afandi, Ahmad Fuad. (2005). Metodologi Pengajaran Bahasa Arab. Malang: Misykat.

Afifah, Nor, \& Sunarto Sunarto, Moh. Fery Fauzi, Irma Anindiati, Talqis Nurdianto. (2020). The Implementation of Mimicry Memorization Method for Novice Students in Learning Arabic Mufradat. Jurnal Al Bayan: Jurnal Jurusan Pendidikan Bahasa Arab, 12(2), 263-280. https://doi.org/10.24042/albayan. v.12i2.5953.

Arikunto, Suharsimi. (20 1 7). Prosedur Penelitian Suatu Pendekatan Praktik. Jakarta: Rineka Cipta.

Arsyad, Azhar. (2010). Bahasa Arab dan Metode Pengajarannya. Yogyakarta: Pustaka Pelajar.

Chalik, Sitti Aisyah. (2020). Metode Langsung (Al-Tarīqah Al-Mubāsyarah) dan Strategi Pembelajarannya, 8(2), 161-168. Shaut Al Arabiayah: Jurnal Pendidikan Bahasa Arab. http://journal.uin-alauddin.ac.id/index.php/Shautul-Arabiyah/article/ view/17788.

Danim, Sudarwan. (2013). Menjadi Peneliti Kualitatif Ancangan Metodologi, Presentasi, dan Publikasi Penelitian untuk Mahasiswa dan Peneliti Pemula Bidang Ilmu-Ilmu Sosial, Pendidikan dan Humaniora. Bandung: Pustaka Setia.

Fadli, Muhammad Rijal. (2021). Memahami Desain Metode Penelitian Kualitatif. 21 (1.) Humanika: Kajian Ilmiah Mata Kuliah Umum. http://journal.uny.ac.id/index.php/ humanika is licensed under a Creative Commons Attribution-Non Commercial 4.0 International License. https:// doi.org/10.21831/hum.v21i1.38075.

Khalilullah, M. (2012). Permainan Teka-Teki Silang sebagai Media dalam Pembelajaran Bahasa Arab (Mufradat). Jurnal An-nida', 37(1), 15-26. http://ejournal.uinsuska.ac.id/index.php/Anida/article/download/309/292 http://dx.doi.org/10. 24014/an-nida.v37i1.309.

Medikawati, Julie. (2012). Membuat Anak Gemar dan Pintar Bahasa Asing. Jakarta: Visimedia.

Mustofa, Syaiful. (2011). Strategi Pembelajaran Bahasa Arab Inovatif. Malang: UIN-Maliki Press. 
Muhammad. (2013). Metodologi penelitian ekonomi islam: pendekatan kuantitatif. Jakarta: PT. Raja Grafindo Persada.

Mustakim. (2011). Strategi dan Metode Pembelajaran. Pekalongan: STAIN Pekalongan Press.

Moleong, Lexy J. (2018). Metodologi penelitian kualitatif. Bandung: PT Remaja Rosdakarya.

Natsir, Nurasia. (2017). Hubungan Psikoliguistik dalam Pemerolehan dan Pembelajaran Bahasa. Jurnal Retorika. 10(1), 20-30. Retrived from https://ojs.unm.ac.id $>$ retorika>article $>$ download.

Rafiq bin Ghufron, Ainur. (2013). Ringkasan Kaidah-Kaidah Bahasa Arab. Gresik: Pustaka Al-Furqon Al-Islam.

Rubini \& Hani, Zahrani. (2020). Kajian Teoritis Metodologi Pembelajaran Bahasa Arab. Jurnal Pendidikan Bahasa Arab, 3(1), 25-44. http://www.journal.staimsyk.ac.id/ index.php/ihtimam/article/view/220. https://doi.org/10. 36668/jih.v3i1.220.

Sesep, A., \& Munawar, M. (2012) Metode Cepat Menghafal $1000++$ Vocabulary \& 16 Tenses. Jakarta: Mediakita.

Usman, H., \& Punomo S. A. (2019). Metodologi Penelitian Sosial. Jakarta :PT Bumi Aksara.

Wa, Muna. (2011). Metodologi Pembelajaran Bahasa Arab Teori dan Aplikasi Teori dan Aplikasi. Jakarta: Penerbit Press.

Wattimena, Reza A. A. (2011). Metodologi Penelitian Filsafat. Yogyakarta: Kanisius.

Yusuf, T., \& Syaiful, A. (1997). Metodologi Pengajaran Agama dan Bahasa Arab. Jakarta: Grafindo Persada. 